\title{
The Use of Effective Language and Communication in the Management of Obesity: the Challenge for Healthcare Professionals
}

\author{
Sameera Auckburally ${ }^{1,2}$ (D) Elena Davies ${ }^{1} \cdot$ Jennifer Logue ${ }^{1}$ \\ Accepted: 29 April 2021 / Published online: 18 May 2021 \\ (C) The Author(s) 2021
}

\begin{abstract}
Purpose of Review Initial conversations about weight with patients are important to set the tone for future dialogue and management of obesity. There is often reluctance in raising the topic of overweight or obesity in consultations. We aimed to evaluate literature to discover the perceived barriers to optimal discussion about weight status and preferred weight-based terminology for adults, adolescents and parents of younger children.

Recent Findings Fear of offending patients, insufficient training and lack of knowledge of referral pathways were identified as factors hindering healthcare professionals' ability to discuss weight with patients. Neutral terms, such as 'weight', were preferred by patients, with 'fat' and 'obese' viewed as undesirable and stigmatising words.

Summary There is a need for greater support and provision of specific training, including education on communicating weight status, for those involved in the management of obesity. More research is necessary to assess the impact of interventions to improve initial discussions with patients about weight.
\end{abstract}

Keywords Obesity $\cdot$ Language $\cdot$ Communication $\cdot$ Person-first $\cdot$ Paediatric obesity $\cdot$ Healthcare

\section{Introduction}

It has been established that people with obesity face prejudice and discrimination as a consequence of their weight $[1,2]$. This is pervasive across age groups and different settings, including schools, workplaces, the media and in healthcare [1], with stigmatising experiences having negative consequences on psychological well-being and physical health [3].

It has been reported that people with overweight and obesity have differing experiences of healthcare compared to those with a lower body mass index (BMI) [4], with patients

Sameera Auckburally and Elena Davies contributed equally to this work. Sameera Auckburally and Elena Davies are joint first authors.

This article is part of the Topical Collection on Health Services and Programs

Sameera Auckburally

sameera.auckburally@nhs.net

1 Faculty of Health and Medicine, Health Innovation One, Sir John Fisher Drive, Lancaster University, Lancaster LA1 4AT, UK

2 Department of Paediatrics, Blackpool Victoria Hospital, Whinney Heys Rd, Blackpool FY3 8NR, UK with obesity citing previous disrespectful treatment and negative attitudes from healthcare professionals as barriers to seeking further medical care [5]. Stigmatising communica- tion in the medical setting can exacerbate the problem. The language healthcare professionals use in weight-based consultations can have an impact on how one feels about their condition [6]. Increasing evidence of weight bias in healthcare has led to policy recommendations and consensus statements outlining the importance of respectful communication about weight with the use of non-stigmatising language [7-9].

This review article aims to evaluate the literature on the perspectives of patients and healthcare professionals on the topic of weight-based communication in clinical practice, both in adult medicine and in the paediatric setting. Interventions to reduce stigma and improve communication of weight status to patients will also be discussed in this review, along with future research needs.

\section{The Views of Patients}

Stigma surrounding obesity and weight results in challenges for both healthcare professionals and patients when it comes 
to raising this topic in a consultation. Qualitative data from patient interviews indicated the language used by health professionals is deemed crucial by patients, as it influences their consultation experience and how comfortable they feel discussing their weight [10].

By way of questionnaires, studies conducted across the UK, the USA and Australia have investigated the desirability of various terms that may be used by clinicians when discussing weight issues with their patients $[10-13,14 \cdot]$. The terms 'weight' and 'BMI' were found to be the preferred and least offensive terms, whilst 'fatness' was reported to be the least desirable word of those offered [11, 12]. Other terms such as 'obese, 'large size' and 'excess fat' were also rated as undesirable [10-13], with 'morbidly obese', 'fat' and 'obese' viewed as the most stigmatising and blameful words [14•]. Indeed, qualitative studies found many patients rejected the label 'obese' due to feelings of stigma and discrimination [ $[15$, 16]. Preferred and disliked weight-based terminology can be found in Table 1.

Weight-based terminology perceived as more desirable from patients' perspectives is not always used by health professionals. One patient, interviewed as part of a study conducted in rural areas of Australia, described a personal experience in which the language used by their doctor bought them to tears [22]. A negative experience such as this may lead to a patient avoiding the topic of obesity in future consultations and therefore missing the opportunity to be referred to support services. This stresses the importance of outlining the most desirable language based on patients' perspectives.

A healthcare professional's choice of language and communication with their patient is likely to be influenced by their attitudes and personal beliefs. Malterud et al. used focus groups to explore patients' personal experiences with weight management in general practice [23]. Patients often felt a negative attitude towards obesity was held by the health professionals caring for them, with feelings of guilt, shame and humiliation described by patients believing they were being

Table 1 Language preferred by patient groups in weight-based consultations

\begin{tabular}{lll}
\hline & Preferred language & Disliked language \\
\hline Adults & Weight & Fatness \\
{$[10-13,14 \cdot]$} & BMI & $\begin{array}{l}\text { Obese } \\
\text { Large size } \\
\end{array}$ \\
& & Fat \\
& Excess fat \\
Adolescents & Weight & Obese \\
{$[17 \bullet, 18 \cdot]$} & Weight problem & Large \\
& Plus-size & Fat \\
Parents of younger & Gaining too much weight & Overweight \\
children & Too much weight for his/her & Obese \\
{$[18 \cdot, 19-21]$} & health & Fat \\
\hline
\end{tabular}

blamed for their weight issues by their clinician [23]. Weight bias in healthcare can result in the avoidance of patients engaging in conversations regarding obesity.

Several studies have conducted qualitative interviews with patients on their experiences of the management of obesity in primary care [23-25]. Patients reported a need for health professionals to receive further training in the management of patients with obesity [23-25]; there was an overall lack of knowledge of support services [23]. In addition, patients complained of insufficient engagement from clinicians in the treatment of obesity. These factors led to patients being disappointed by the lack of enthusiasm, attention and support offered by their general practitioner, and some patients attributed this to their poor success in being able to make and sustain lifestyle changes [23]. Patients also stated that they had received contradictory advice from healthcare professionals on the management of obesity, which created a great deal of frustration and decreased their motivation to manage their weight [25].

Some patients appeared motivated in seeking help from their clinician for weight-related issues, however faced barriers during the process $[22,24,25]$. Patients discussed a reluctance amongst general practitioners to enter conversations regarding obesity [25], whilst other patients wishing to raise weight-related concerns identified restrictions on consultation time as a barrier in doing so [22]. Many patients described feeling dismissed and rushed by their clinician [22]. The lack of regular consultation appointments was also expressed as an important issue for those who wanted an individual plan to guide their weight loss [24]. This research indicates barriers to weight discussion still exist even for patients who raise concerns themselves.

\section{The Views of Healthcare Professionals}

Interviews and focus groups investigating the challenges accompanying the management of obesity from the perspective of healthcare professionals found similar barriers to those reported by patients [25-32]. One is a belief that the interventions available for the management of obesity are not effective [26-28, 32]. Some professionals attributed this to other medical conditions that their patients may have. For example, a patient with limited mobility or one that takes medications associated with weight gain may find it challenging to reduce their weight [27]. Other professionals held a bias towards patients with overweight, believing they lack the motivation and willpower to succeed in a weight management programme [25-27, 32].

Interestingly, qualitative research gathered from medical professionals across the UK, the USA, Sweden and the Netherlands demonstrated a shared opinion that obesity is not a disease and therefore not within a clinician's 
responsibility to address or manage, unless there was an associated co-morbidity $[25,27,28,30]$. Ideas regarding the prevention of obesity at a public health level were mentioned; however, the management for current obesity was seen as less important [27].

Health professionals across the UK, the USA and Sweden perceived lack of skills, knowledge and guidance as barriers in discussing obesity with their patients [25, 27, 28, 30, 32]. Clinicians mentioned they were fearful to raise the issue of obesity as it may offend patients or have detrimental effects on their relationship $[25,29 \bullet, 31,32]$. In addition to a lack of skills required to hold a conversation about obesity, professionals also admitted to lacking knowledge of the referral options for patients with obesity [32]. Due to the recognition of gaps in their knowledge and skills, many professionals expressed low confidence in their capabilities and a desire to gain better training and support in this area [27, 29•, 31].

Furthermore, results from research, including general practitioners, nurses, physiotherapists, dieticians and community nurses working in the Netherlands, indicated health professionals may be avoiding conversations regarding obesity if they believe their patients are not themselves aware of their weight problems [25]. A physiotherapist described multiple consultations in which patients were surprised to discover their BMI was categorised as unhealthy [25]. Concerns about initiating an unexpected conversation on a sensitive topic also add to healthcare professionals' fears of offending their patients [25].

A good doctor-patient relationship was viewed as important by patients and was also valued by doctors as an aspect that provides them with the confidence to engage in conversation with patients about obesity [31]. General practitioners reported having knowledge of a patient's social circumstances allows them to determine if a patient is 'ready' to discuss weight issues and how successful they may be on a management programme [31]. However, not all clinicians have the advantage of being familiar with their patient and having knowledge of their social situation. This is therefore another possible barrier to initiating a discussion about obesity that needs to be addressed.

\section{Interventions}

As outlined previously, both patients and healthcare professionals have various concerns surrounding communication on the topic of obesity in the healthcare setting. The issues described may lead to neglect in discussions about obesity and could prevent patients receiving the support and management they need. This highlights a requirement for these concerns to be recognised and challenged, so clinicians can be confident communicating with their patients in a way that is empathetic and sensitive from the viewpoint of patients.
Interventions to reduce these issues have been implemented in clinical practice, with many focusing on educating health professionals to reduce the stigma surrounding obesity [33••, 34]. O'Brien et al. conducted a study educating students enrolled in a health promotion/public health undergraduate degree programme on how uncontrollable factors, such as genetics and socioeconomic conditions, are associated with obesity [33••]. Its results found a reduction in anti-fat prejudice within the education group compared to the control group [33••]. The same study also showed that providing education focusing on the more controllable causes of obesity, such as diet and exercise, can lead to an increase in anti-fat prejudice [33*0]. This demonstrates that both stigma and prejudice can be influenced by education, and the importance of including uncontrollable causes of obesity within education must not be overlooked.

Research by Kushner et al. also showed an educational intervention to likely be beneficial for the management of obesity in clinical practice [34]. After education, study participants showed an increase in their empathy towards obesity and a reduction in obesity stereotyping [34]. The largest improvement was seen in the participants' confidence levels during interaction with a simulated patient, with improvements in empathy and confidence still apparent one year after the educational intervention [34]. Improving factors such as these is likely to lead to improved communication between patients and clinicians and a higher level of self-efficiency amongst health professionals to refer patients to weight support services, further emphasising the value of educational interventions for current and future health professionals.

Training programmes have also been used to address the issues that stem from a lack of skills and knowledge regarding obesity amongst health professionals $[35,36 \cdot \bullet]$. A programme, which provided interactive training courses, to twenty-nine family practitioners on monitoring and treating obesity, found an association between training and the referral of patients to support services [35]. In contrast, Jay et al. conducted a study to assess the impact of the 5 As counselling framework, an evidence-based training programme on counselling patients with obesity [36••]. However, this did not find professionals who had received training to be more likely to counsel patients with obesity than those who had not received training [36••]. Interestingly, regardless of the selfefficacy of clinicians to counsel or refer patients, both studies found that an increase in the quality of counselling for patients was evident after completion of the training course $[35,36 \bullet \cdot]$. The differences found between these studies highlight the need for further investigation into the most effective training techniques. Hopefully, future research will clarify the techniques that are best able to improve the communication and management of patients with obesity. By implementing these techniques in clinical practice, the satisfaction of both patients and health professionals in the communication surrounding obesity can be increased. 


\section{The Views of Paediatric Patients and Families}

Weight-based victimisation in the paediatric population tends to stem from peers, families and teachers. These stigmatising experiences in their formative years can have long-term consequences on physical and mental health, namely maladaptive eating behaviours, weight gain, low self-esteem and depressive symptoms [2]. Weight labelling can initiate the processes of stigma; hence, it is important that healthcare professionals appreciate the long-lasting effect of words and use non-biased language [37].

Puhl et al. found that American adolescents prefer healthcare providers to use 'weight', 'weight problem' or 'plus size' when discussing body weight. 'Obese', 'large' and 'fat' received lower preference ratings [17•]. Whilst 'curvy' was a term preferred by females if used by their family members [38], it received the third lowest preference rating if used by healthcare professionals [17•]. Interestingly, no words achieved ratings greater than 4 on the 5 -point rating scale and most words received a mean score in the region of the mid-point of the scale. This could be in part due to the sample of participants having high internalised weight stigma scores and potentially increased sensitivity to even more neutral weight-based terms. With varying preferences noted according to gender, BMI and extent of internalised weight stigma, it may be prudent for clinicians to acknowledge this and ask adolescents about their language preferences $[17 \bullet$, 39•].

There is a paucity of research into younger children's perspectives on weight-based terminology, with two studies in the Netherlands identified [18•, 40]. $44.6 \%$ of children had experienced a clinician using a term that they disliked [18•]. Many words, such as 'adiposity', 'BMI' and 'morbid obesity', were unfamiliar to the majority of children. 'Fat' was disliked the most by children [18•]; its appropriateness was doubted in the healthcare setting, with many reporting negative connotations from previous bullying [40].

All parents that had a child with overweight reported that the choice of words mattered, with the term 'gaining too much weight' preferred over 'overweight', 'fat' and 'obese' [19]. This has been echoed by other research finding the terms 'fat', 'obese' and 'chubby' to be viewed as the most stigmatising and blaming by parents [20]. There was agreement amongst English- and Spanish-speaking Latino parents in the USA that the term 'too much weight for his/her health' ('demasiado peso para su salud') was the most motivating, but also acknowledged that any weight-related word could potentially be viewed as insulting, rather it is how it is said that can determine how offensive it is believed to be [21]. If parents believed their child to be stigmatised about their weight by a doctor, $37 \%$ would feel upset and embarrassed and $24 \%$ would avoid future appointments, highlighting the importance of sensitivity in the consultation [20].
When addressing the topic of overweight or obesity in a child, some parents strongly believe it is inappropriate for a clinician to do so when meeting a family for the first time [39.]; $68 \%$ of parents would prefer clinicians to outline their concerns with the child present, with the hope it would convey the importance of the problem, albeit using a sensitive approach. Of those that disagreed, $17 \%$ expressed concerns about lowering the child's self-esteem and increasing the risk of eating disorders [19].

Open-ended questions and a respectful tone were highly endorsed by children and parents when discussing weight [39]. Female adolescents with overweight or obesity reported being more receptive to clinicians that included them in the conversation and expressed interest in their lives [41••]. The same study noted that participants were highly sensitive to weight-related communication, which often left them feeling insecure and upset. They much preferred a gentle, encouraging approach with a changed focus from weight management to health management $[41 \bullet \bullet]$.

\section{The Views and Experiences of Healthcare Professionals in the Paediatric Setting}

With the rising prevalence of paediatric obesity, healthcare professionals are increasingly discussing weight-based health with young patients and their families. These consultations can be perceived as a challenge, with some general practitioners reluctant to have the 'difficult conversation' with parents and children [42, 43]. 86.7\% of school nurses in Missouri also believed counselling families about weight loss was difficult, but not inconvenient (51.9\%) [44].

Johnson et al. found that school nurses in Solihull, England, felt introducing the subject of obesity as particularly problematic, either in person or via written correspondence [42]. In England, letters are sent to parents after a national measurement programme is conducted in primary schools. These letters detail the child's body mass index and related health risks [45]. School nurses had faced backlash from some parents upon the receipt of these letters, which then acted as a barrier to further meaningful weight-related discussions and referral to lifestyle interventions [42].

Other healthcare professionals have expressed a fear of parental reaction as limiting their capacity to counsel on weight as they were often worried that parents would feel offended and personally judged on their lifestyle or parenting skills [46, 47]. This would lead to avoidance of the topic entirely by a few healthcare professionals to prevent jeopardising the professional-parent relationship [48].

General practitioners acknowledged a role in raising the issue of a child's weight but felt time constraints in a busy surgery often prevented them from doing so [43]. Time was highlighted as a common barrier to meaningful discussions 
about weight amongst other healthcare professionals too [49-50, 51••]. This was supported by research showing that paediatricians that spent more time with families during routine well-care appointments were more likely to counsel on the maintenance of a healthy weight [52].

Limited experience and lack of training have also been highlighted as barriers to addressing childhood obesity [53]. School nurses described a perceived lack of knowledge in leading a motivational conversation about weight management with families [54]. General practitioners in Australia strongly felt that they should offer treatment to children with overweight or obesity rather than referring to others, but only $29 \%$ felt professionally well prepared to manage childhood obesity [55] and half of the clinicians in rural US family practices reported that they did not have enough expertise to create a structured dietary plan [56]. Healthcare professionals generally expressed concern about the lack of access to clear guidance or referral pathways leading to inconsistent practice based on individual judgement [32, 53, 57].

In terms of weight-based language preferences, a Dutch study reported that healthcare professionals used the terms 'overweight', 'BMI' and 'healthy weight' most often in consultations with children and parents [18•]. Interestingly, healthcare professionals gave the highest preference rating to 'BMI', a term that the majority of children were unfamiliar with. This was the only study found that identified healthcare professionals' preferences of weight-based terminology in paediatric clinical practice; interestingly, it noted the differences in preferences between children, parents and clinicians, warranting further research in this area.

Healthcare professionals regarded the use of objective tools, such as growth charts, as important in presenting the issue of weight in a less judgemental fashion [48, 58••, 59]. Another factor viewed as a facilitator in initiating the discussion of weight was having an established strong relationship with parents [60]. General practitioners noted that the conversation about weight with families should be done 'carefully and subtly', an approach that had helped had been to move the discussion from presenting symptoms, such as joint pain, towards how weight may affect those symptoms and how losing weight could potentially improve them [42].

\section{Interventions and Recommendations within the Paediatric Setting}

Conversations with young people about weight have the potential to impact their physical and mental health for the rest of their lives. It is therefore crucial that healthcare professionals ensure these discussions are handled appropriately.

Interviews with healthcare professionals [46], crosssectional surveys of parents [19] and focus groups with young people and their caregivers [39•] have supported involving both children and parents in consultations regarding weight. This should ideally be with a healthcare professional that has a longstanding relationship with the family in order to engage all relevant stakeholders in affecting change in the household $[61,62]$. However, all clinicians, regardless of the duration of relationship with the family, have a responsibility to initiate weight-related discussions as early as possible in order to prevent obesity [63].

In order to mitigate weight stigmatisation, in 2017, The American Academy of Pediatrics made recommendations for paediatricians, which included the importance of recognising the complex aetiology of obesity to help prevent stereotyping individuals with overweight or obesity [8]. They also advocated for the use of person-first language and neutral words when describing weight. It may be appropriate to consider asking adolescents and parents on their preferred terms when discussing weight, due to preference variations amongst different cultures and genders $[17 \cdot, 21,38]$. Objective communication tools, such as growth charts, may help in presenting the child's weight status in a visual, non-judgemental manner to aid discussion [58••, 59, 64].

Greater support and provision of specific training, including education on communicating weight status, for those involved in the management of paediatric obesity would be incredibly useful, given that limited knowledge and lack of training were widely perceived as barriers to effective communication [53, 57, 65]. Training concentrating on developing confidence in having conversations about weight would allow healthcare professionals to become more proficient in raising the issue with children and their families.

There has been a lack of research into the impact of interventions to improve initial discussions with families about weight. There have been more studies, however, assessing motivational interviewing in paediatric obesity, which is a patient-centred communication style used to modify health behaviour [66, 67]; it has been found to improve BMI $z$-scores $[68,69]$ and increase autonomous motivation in engaging in a healthier lifestyle [70]. Due to its use as more of a treatment with ongoing clinician follow-ups, it is outside the remit of this review, however improving training in the motivational interviewing technique could improve the confidence in healthcare professionals' ability to discuss weight, therefore increasing the ease of bringing up the topic opportunistically.

\section{Conclusion}

In both paediatric and adult obesity management, there were similar concerns raised from patients and healthcare professionals surrounding consultations about weight. The lack of training and knowledge of referral pathways hindered 
clinicians' ability to bring up the topic of weight. Fear of offending patients and families added to the perceived challenge of discussing weight with patients.

It is important for healthcare professionals to seek permission to discuss weight. Patients advocated for a sensitive and respectful approach, with the use of neutral terminology, such as 'weight', rather than 'obese' or 'fat'. It may be sensible to ask patients about their language preferences, especially as varying preferences were noted amongst adolescents of different genders and according to the extent in which they internalised weight stigma.

Educating healthcare professionals on the underlying causes of obesity, including the many uncontrollable factors, can help to reduce the prejudice towards patients with obesity and increase confidence in discussing weight with them. Training directed at developing skills, knowledge and confidence in having conversations about weight would allow for healthcare professionals to more easily raise the topic with patients and families.

\section{Declarations}

Disclosure JL has disclosed grants/contracts received from the National Institute for Health Research and British Heart Foundation to her institution. Novo Nordisk have provided consulting fees to her institution and given support to attend meetings. This has been documented in the disclosure form.

Human and Animal Rights and Informed Consent This article does not contain any studies with human or animal subjects performed by any of the authors.

Open Access This article is licensed under a Creative Commons Attribution 4.0 International License, which permits use, sharing, adaptation, distribution and reproduction in any medium or format, as long as you give appropriate credit to the original author(s) and the source, provide a link to the Creative Commons licence, and indicate if changes were made. The images or other third party material in this article are included in the article's Creative Commons licence, unless indicated otherwise in a credit line to the material. If material is not included in the article's Creative Commons licence and your intended use is not permitted by statutory regulation or exceeds the permitted use, you will need to obtain permission directly from the copyright holder. To view a copy of this licence, visit http://creativecommons.org/licenses/by/4.0/.

\section{References}

Papers of particular interest, published recently, have been highlighted as:

- Of importance

-• Of major importance

1. Puhl RM, Heuer CA. The stigma of obesity: a review and update. Obesity Silver Spring. 2009;17(5):941-64. https://doi.org/10.1038/ oby.2008.636.
2. Puhl RM, Lessard LM. Weight stigma in youth: prevalence, consequences, and considerations for clinical practice. Curr Obes Rep. 2020;9(4):402-11. https://doi.org/10.1007/s13679-020-00408-8.

3. Wu YK, Berry DC. Impact of weight stigma on physiological and psychological health outcomes for overweight and obese adults: a systematic review. J Adv Nurs. 2018;74(5):1030-42. https://doi. org/10.1111/jan.13511.

4. Hayward LE, Neang S, Ma S, Vartanian LR. Discussing weight with patients with overweight: supportive not stigmatizing conversations increase compliance intentions and health motivation. Stigma and Health. 2020;5(1):53-68.

5. Amy NK, Aalborg A, Lyons P, Keranen L. Barriers to routine gynecological cancer screening for White and African-American obese women. Int J Obes. 2006;30(1):147-55. https://doi.org/10. 1038/sj.ijo.0803105.

6. Puhl RM. What words should we use to talk about weight? A systematic review of quantitative and qualitative studies examining preferences for weight-related terminology. Obes Rev. 2020;21(6): e13008. https://doi.org/10.1111/obr.13008.

7. Albury C, Strain WD, Brocq SL, Logue J, Lloyd C, Tahrani A, et al. The importance of language in engagement between healthcare professionals and people living with obesity: a joint consensus statement. Lancet Diabetes Endocrinol. 2020;8(5):447-55. https:// doi.org/10.1016/S2213-8587(20)30102-9.

8. Pont SJ, Puhl R, Cook SR, Slusser W, Section On O, Obesity S. Stigma experienced by children and adolescents with obesity. Pediatrics. 2017;140(6). https://doi.org/10.1542/peds.2017-3034.

9. American Medical Association. Person-first language for obesity H-440.821. 2017. https://policysearch.ama-assn.org/policyfinder/det a i $1 /$

obesity\%20and\%20language?uri=\%2FAMADoc\%2FHOD.xml-H440.821.xml.

10. Glenister K, Opie CA, Wright J. Preferred language regarding overweight and obesity in general practice: a survey of predominantly rural Australian adults. Aust J Prim Health. 2018;24(5):391-7. https://doi.org/10.1071/PY18023.

11. Volger S, Vetter ML, Dougherty M, Panigrahi E, Egner R, Webb $\mathrm{V}$, et al. Patients preferred terms for describing their excess weight: discussing obesity in clinical practice. Obesity Silver Spring. 2012;20(1):147-50. https://doi.org/10.1038/oby.2011.217.

12. Dutton GR, Tan F, Perri MG, Stine CC, Dancer-Brown M, Goble $\mathrm{M}$, et al. What words should we use when discussing excess weight? J Am Board Fam Med. 2010;23(5):606-13. https://doi. org/10.3122/jabfm.2010.05.100024.

13. Gray CM, Hunt K, Lorimer K, Anderson AS, Benzeval M, Wyke S. Words matter: a qualitative investigation of which weight status terms are acceptable and motivate weight loss when used by health professionals. BMC Public Health. 2011;11:513. https://doi.org/10. 1186/1471-2458-11-513.

14. Puhl R, Peterson JL, Luedicke J. Motivating or stigmatizing? Public perceptions of weight-related language used by health providers. Int J Obes. 2013;37(4):612-9. https://doi.org/10.1038/ijo. 2012.110 This study yields qualitative data that indicates which weight-based terms used by health professionals are favoured by patients. It also explores which terms may motivate weight loss.

15. Ward SH, Gray AM, Paranjape A. African Americans' perceptions of physician attempts to address obesity in the primary care setting. J Gen Intern Med. 2009;24(5):579-84. https://doi.org/10.1007/ s11606-009-0922-z.

16. Batsis JA, Zagaria AB, Brooks E, Clark MM, Phelan S, LopezJimenez $\mathrm{F}$, et al. The use and meaning of the term obesity in rural older adults: a qualitative study. J Appl Gerontol. 2021;40(4):42332. https://doi.org/10.1177/0733464820903253.

17. Puhl RM, Himmelstein MS. Adolescent preferences for weight terminology used by health care providers. Pediatr Obes. 
2018;13(9):533-40. https://doi.org/10.1111/ijpo.12275 The first study to assess adolescent perceptions of weight-based language from healthcare providers. It also examined the differences in preferences by gender, weight and internalised stigma.

18. van Maarschalkerweerd PEA, Camfferman R, Seidell JC, Halberstadt J. Children's, parents' and healthcare professionals' preferences for weight-based terminology in health care. Health Commun. 2020:1-5. https://doi.org/10.1080/10410236.2020. 1796282 This study published in $\mathbf{2 0 2 0}$ provides insights into the differences between healthcare professionals' and children's preferences of weight-based language in the Netherlands. It is also the only study identified that includes preferred language from children.

19. Eneli IU, Kalogiros ID, McDonald KA, Todem D. Parental preferences on addressing weight-related issues in children. Clin Pediatr Phila. 2007;46(7):612-8. https://doi.org/10.1177/ 0009922807299941.

20. Puhl RM, Peterson JL, Luedicke J. Parental perceptions of weight terminology that providers use with youth. Pediatrics. 2011;128(4): e786-93. https://doi.org/10.1542/peds.2010-3841 Quantitative assessment of parents' preferences for weight-based terminology used to described their child's weight and whether they associated certain words with stigma or motivation to lose weight.

21. Knierim SD, Rahm AK, Haemer M, Raghunath S, Martin C, Yang A, et al. Latino parents' perceptions of weight terminology used in pediatric weight counseling. Acad Pediatr. 2015;15(2):210-7. https://doi.org/10.1016/j.acap.2014.11.003.

22. Glenister KM, Malatzky CA, Wright J. Barriers to effective conversations regarding overweight and obesity in regional Victoria. Aust Fam Physician. 2017;46(10):769-73 This study includes both patient and general practitioner perspectives of the multiple factors that may prevent effective weight-related conversations taking place in primary care.

23. Malterud K, Ulriksen K. Obesity in general practice: a focus group study on patient experiences. Scand J Prim Health Care. 2010;28(4):205-10. https://doi.org/10.3109/02813432.2010. 526773 A focus group study indicating that patients with obesity have a desire for their clinicians to discuss weight issues with them. It also highlights a possible insufficient engagement and knowledge of services amongst general practitioners that may reduce the referral of patients for management of obesity.

24. Heintze C, Sonntag U, Brinck A, Huppertz M, Niewohner J, Wiesner J, et al. A qualitative study on patients' and physicians' visions for the future management of overweight or obesity. Fam Pract. 2012;29(1):103-9. https://doi.org/10.1093/fampra/cmr051.

25. Derksen RE, Brink-Melis WJ, Westerman MJ, Dam JJ, Seidell JC, Visscher TL. A local consensus process making use of focus groups to enhance the implementation of a national integrated health care standard on obesity care. Fam Pract. 2012;29(Suppl 1):i177-i84. https://doi.org/10.1093/fampra/cmr072.

26. Claridge R, Gray L, Stubbe M, Macdonald L, Tester R, Dowell AC. General practitioner opinion of weight management interventions in New Zealand. J Prim Health Care. 2014;6(3):212-20.

27. Hansson LM, Rasmussen F, Ahlstrom GI. General practitioners' and district nurses' conceptions of the encounter with obese patients in primary health care. BMC Fam Pract. 2011;12:7. https://doi.org/ 10.1186/1471-2296-12-7.

28. Alexander SC, Ostbye T, Pollak KI, Gradison M, Bastian LA, Brouwer RJ. Physicians' beliefs about discussing obesity: results from focus groups. Am J Health Promot. 2007;21(6):498-500. https://doi.org/10.4278/0890-1171-21.6.498.

29. Jochemsen-van der Leeuw HG, van Dijk N, Wieringa-de Waard M. Attitudes towards obesity treatment in GP training practices: a focus group study. Fam Pract. 2011;28(4):422-9. https://doi.org/10.1093/ fampra/cmq110.
30. Gunther S, Guo F, Sinfield P, Rogers S, Baker R. Barriers and enablers to managing obesity in general practice: a practical approach for use in implementation activities. Qual Prim Care. 2012;20(2):93-103.

31. Ashman F, Sturgiss E, Haesler E. Exploring self-efficacy in Australian general practitioners managing patient obesity: a qualitative survey study. Int J Family Med. 2016;2016:8212837. https:// doi.org/10.1155/2016/8212837.

32. Nolan C, Deehan A, Wylie A, Jones R. Practice nurses and obesity: professional and practice-based factors affecting role adequacy and role legitimacy. Prim Health Care Res Dev. 2012;13(4):353-63. https://doi.org/10.1017/S1463423612000059.

33.• • O'Brien KS, Puhl RM, Latner JD, Mir AS, Hunter JA. Reducing anti-fat prejudice in preservice health students: a randomized trial. Obesity Silver Spring. 2010;18(11):2138-44. https://doi.org/10. 1038/oby.2010.79.

34. Kushner RF, Zeiss DM, Feinglass JM, Yelen M. An obesity educational intervention for medical students addressing weight bias and communication skills using standardized patients. BMC Med Educ. 2014;14:53. https://doi.org/10.1186/1472-6920-14-53 Medical students had a change in their attitudes and beliefs towards obesity after being enrolled in an obesity educational intervention, demonstrating the utility of educational interventions for current and future health professionals.

35. Katz S, Feigenbaum A, Pasternak S, Vinker S. An interactive course to enhance self-efficacy of family practitioners to treat obesity. BMC Med Educ. 2005;5(1):4. https://doi.org/10.1186/14726920-5-4.

36.• Jay M, Schlair S, Caldwell R, Kalet A, Sherman S, Gillespie C. From the patient's perspective: the impact of training on resident physician's obesity counseling. J Gen Intern Med. 2010;25(5):41522. https://doi.org/10.1007/s11606-010-1299-8.

37. Hunger JM, Tomiyama AJ. Weight labeling and obesity: a longitudinal study of girls aged 10 to 19 years. JAMA Pediatr. 2014;168(6):579-80. https://doi.org/10.1001/jamapediatrics.2014. 122.

38. Puhl RM, Himmelstein MS, Armstrong SC, Kingsford E. Adolescent preferences and reactions to language about body weight. Int J Obes. 2017;41(7):1062-5. https://doi.org/10.1038/ ijo.2017.55.

39. McPherson AC, Knibbe TJ, Oake M, Swift JA, Browne N, Ball GDC, et al. Fat is really a four-letter word: exploring weight-related communication best practices in children with and without disabilities and their caregivers. Child Care Health Dev. 2018;44(4):63643. https://doi.org/10.1111/cch.12575.

40. Stuij M, van Maarschalkerweerd PEA, Seidell JC, Halberstadt J, Dedding C. Youth perspectives on weight-related words used by healthcare professionals: a qualitative study. Child Care Health Dev. 2020;46(3):369-80. https://doi.org/10.1111/cch.12760.

41.• Yerges AL, Snethen JA, Carrel AL. Female adolescents with overweight and obesity share their perspectives on the clinical setting and weight management. Clin Obes. 2021;11(1):e12415. https:// doi.org/10.1111/cob.12415 Interviews with female adolescents found that they wanted to be included in conversations about weight and responded positively if the clinician took an interest in their lives.

42. Johnson RE, Oyebode O, Walker S, Knowles E, Robertson W. The difficult conversation: a qualitative evaluation of the 'Eat Well Move More' family weight management service. BMC Res Notes. 2018;11(1):325. https://doi.org/10.1186/s13104-0183428-0.

43. Walker O, Strong M, Atchinson R, Saunders J, Abbott J. A qualitative study of primary care clinicians' views of treating childhood obesity. BMC Fam Pract. 2007;8:50. https://doi.org/10.1186/14712296-8-50. 
44. Moyers P, Bugle L, Jackson E. Perceptions of school nurses regarding obesity in school-age children. J Sch Nurs. 2005;21(2):86-93. https://doi.org/10.1177/10598405050210020501.

45. Public Health England. National Child Measurement Programme operational guidance 2020. In: England PH, editor. London: PHE publications; 2019 1-67

46. Isma GE, Bramhagen AC, Ahlstrom G, Ostman M, Dykes AK. Swedish child health care nurses conceptions of overweight in children: a qualitative study. BMC Fam Pract. 2012;13:57. https://doi. org/10.1186/1471-2296-13-57.

47. Regber S, Marild S, Johansson HJ. Barriers to and facilitators of nurseparent interaction intended to promote healthy weight gain and prevent childhood obesity at Swedish child health centers. BMC Nurs. 2013;12(1):27. https://doi.org/10.1186/1472-6955-12-27.

48. Chamberlin LA, Sherman SN, Jain A, Powers SW, Whitaker RC. The challenge of preventing and treating obesity in low-income, preschool children: perceptions of WIC health care professionals. Arch Pediatr Adolesc Med. 2002;156(7):662-8. https://doi.org/10. 1001/archpedi.156.7.662.

49. King LA, Loss JH, Wilkenfeld RL, Pagnini DL, Booth ML, Booth SL. Australian GPs' perceptions about child and adolescent overweight and obesity: the Weight of Opinion study. Br J Gen Pract. 2007;57(535):124-9.

50. Steele RG, Wu YP, Jensen CD, Pankey S, Davis AM, Aylward BS. School nurses' perceived barriers to discussing weight with children and their families: a qualitative approach. J Sch Health. 2011;81(3): 128-37. https://doi.org/10.1111/j.1746-1561.2010.00571.x.

51.• Sjunnestrand M, Nordin K, Eli K, Nowicka P, Ek A. Planting a seed - child health care nurses' perceptions of speaking to parents about overweight and obesity: a qualitative study within the STOP project. BMC Public Health. 2019;19(1):1494. https://doi.org/10. 1186/s12889-019-7852-4 A recent study conducted in Stockholm County, Sweden which identified that stigmatising attitudes about overweight within society play a role in preventing conversations between parents and healthcare professionals and hence delays optimal management of overweight and obesity.

52. Rattay KT, Fulton JE, Galuska DA. Weight counseling patterns of U. S Pediatricians Obes Res. 2004;12(1):161-9. https://doi.org/10. 1038/oby.2004.21.

53. Rhee KE, Kessl S, Lindback S, Littman M, El-Kareh RE. Provider views on childhood obesity management in primary care settings: a mixed methods analysis. BMC Health Serv Res. 2018;18(1):55. https://doi.org/10.1186/s12913-018-2870-y.

54. Mullersdorf M, Zuccato LM, Nimborg J, Eriksson H. Maintaining professional confidence-monitoring work with obese schoolchildren with support of an action plan. Scand J Caring Sci. 2010;24(1):1318. https://doi.org/10.1111/j.1471-6712.2009.00696.x.

55. Gerner B, McCallum Z, Sheehan J, Harris C, Wake M. Are general practitioners equipped to detect child overweight/obesity? Survey and audit. J Paediatr Child Health. 2006;42(4):206-11. https://doi. org/10.1111/j.1440-1754.2006.00831.x.

56. Findholt NE, Davis MM, Michael YL. Perceived barriers, resources, and training needs of rural primary care providers relevant to the management of childhood obesity. J Rural Health. 2013;29(Suppl 1):s17-24. https://doi.org/10.1111/jrh.12006.

57. Turner GL, Owen S, Watson PM. Addressing childhood obesity at school entry: qualitative experiences of school health professionals. J Child Health Care. 2016;20(3):304-13. https://doi.org/10.1177/ 1367493515587061

58. Bradbury D, Chisholm A, Watson PM, Bundy C, Bradbury N, Birtwistle S. Barriers and facilitators to health care professionals discussing child weight with parents: a meta-synthesis of qualitative studies. Br J Health Psychol. 2018;23(3):701-22. https://doi. org/10.1111/bjhp.12312 A recent and important review of qualitative studies exploring healthcare professionals' perceptions of discussing child weight with parents which showed a high degree of consistency between studies.

59. Barlow SE, Richert M, Baker EA. Putting context in the statistics: paediatricians' experiences discussing obesity during office visits. Child Care Health Dev. 2007;33(4):416-23. https://doi.org/10. 1111/j.1365-2214.2006.00716.x.

60. Edvardsson K, Edvardsson D, Hornsten A. Raising issues about children's overweight-maternal and child health nurses' experiences. J Adv Nurs. 2009;65(12):2542-51. https://doi.org/10.1111/ j.1365-2648.2009.05127.x.

61. Lupi JL, Haddad MB, Gazmararian JA, Rask KJ. Parental perceptions of family and pediatrician roles in childhood weight management. J Pediatr. 2014;165(1):99-103e2. https://doi.org/10.1016/j. jpeds.2014.02.064.

62. Lowenstein LM, Perrin EM, Berry D, Vu MB, Pullen Davis L, Cai J, et al. Childhood obesity prevention: fathers' reflections with healthcare providers. Child Obes. 2013;9(2):137-43. https://doi. org/10.1089/chi.2012.0111.

63. McPherson AC, Hamilton J, Kingsnorth S, Knibbe TJ, Peters M, Swift JA, et al. Communicating with children and families about obesity and weight-related topics: a scoping review of best practices. Obes Rev. 2017;18(2):164-82. https://doi.org/10.1111/obr. 12485.

64. Public Health England. Let's talk about weight: a step-by-step guide to conversations about weight management with children and families for health and care professionals. In: England $\mathrm{PH}$, editor. London: PHE Publications 2017 1-14.

65. Bradbury D, Porcellato L, Timpson H, Turner G, Goodhew S, Young R, et al. Multiple stakeholder views of pre-school child weight management practices: a mixed-methods study. Health Educ J. 2019;78(7):798-811. https://doi.org/10.1177/ 0017896919848019.

66. Resnicow K, McMaster F, Bocian A, Harris D, Zhou Y, Snetselaar L, et al. Motivational interviewing and dietary counseling for obesity in primary care: an RCT. Pediatrics. 2015;135(4):649-57. https://doi.org/10.1542/peds.2014-1880.

67. Davis MM, Gance-Cleveland B, Hassink S, Johnson R, Paradis G, Resnicow K. Recommendations for prevention of childhood obesity. Pediatrics. 2007;120(Suppl 4):S229-53. https://doi.org/10. 1542/peds.2007-2329E.

68. Bean MK, Ingersoll KS, Powell P, Stern M, Evans RK, Wickham EP 3rd, et al. Impact of motivational interviewing on outcomes of an adolescent obesity treatment: results from the MI Values randomized controlled pilot trial. Clin Obes. 2018;8(5):323-6. https:// doi.org/10.1111/cob.12257.

69. Freira S, Lemos MS, Fonseca H, Williams G, Ribeiro M, Pena F, et al. Anthropometric outcomes of a motivational interviewing school-based randomized trial involving adolescents with overweight. Eur J Pediatr. 2018;177(7):1121-30. https://doi.org/10. 1007/s00431-018-3158-2.

70. Dawson AM, Brown DA, Cox A, Williams SM, Treacy L, Haszard $\mathrm{J}$, et al. Using motivational interviewing for weight feedback to parents of young children. J Paediatr Child Health. 2014;50(6): 461-70. https://doi.org/10.1111/jpc. 12518.

Publisher's Note Springer Nature remains neutral with regard to jurisdictional claims in published maps and institutional affiliations. 